\title{
Frontal Fibrosing Alopecia: Role of Dermoscopy in Differential Diagnosis
}

\author{
P. Rubegni F. Mandato M. Fimiani
}

Dermatology Unit, Department of Clinical Medicine and Immunological Sciences, University of Siena, Siena, Italy

\section{Key Words}

Alopecia · Dermoscopy $\cdot$ Menopausal $\cdot$ Lichen planopilaris

\begin{abstract}
Frontal fibrosing alopecia (FFA) is more common in postmenopausal women, but it can occur in younger women. Some authors consider FFA to be a distinct frontal variant of lichen planopilaris. From a clinical point of view, this relatively uncommon condition is characterized by progressive frontotemporal recession due to inflammatory destruction of hair follicles. Dermoscopy can be very useful, as the differential diagnosis between traction alopecia, alopecia areata, FFA and cicatricial marginal alopecia may be difficult. It is not clear whether or not treatment alters the natural history of the disease - the disease stabilized with time in most of the patients with or without continuing treatment. Here we report a case of a 50-year-old woman with FFA and discuss the relevance of dermoscopy in the differential diagnosis of this disease.
\end{abstract}

\section{Introduction}

The use of dermoscopy, initially limited to pigmented lesions, has become an important tool for the diagnosis of nonpigmented skin lesions and in inflammatory and infectious diseases [1]. Here we report a case of postmenopausal frontal fibrosing alopecia (FFA) to confirm the role of dermoscopy in the differential diagnosis of hair and scalp disorders. FFA, first described by Kossard in 1994, is a variety of cicatricial alopecia characterized by selective involvement of the hair of the frontoparietal region of the scalp [2]. Patients present with frontotemporal hair recession and eyebrow loss. The affected scalp is uniformly pale with loss of follicular orifices and the affected hair margin shows perifollicular erythema $[3,4]$. Dermoscopy shows absence of follicular openings, perifollicular scale, and a variable degree of perifollicular erythema [5]. Typical histopathological findings are prominent perifollicular fibrosis and lymphocytic inflammation in a lichenoid pattern around the infundibular isthmus and bulge portions 


\begin{tabular}{l|l|l|l} 
Case Reports $\boldsymbol{h}$ & $\begin{array}{l}\text { Case Rep Dermatol 2010;2:40-45 } \\
\text { D01: } 10.1159 / 000298283\end{array}$ & Published online: April 8, 2010 & $\begin{array}{l}\text { ○ 2010 S. Karger AG, Basel } \\
\text { ISSN 1662-6567 } \\
\text { www.karger.com/cde }\end{array}$ \\
\hline
\end{tabular}

of the follicles [6]. There is a reduction in the number of hair follicles and replacement by fibrous tracts. These findings are indistinguishable from those of lichen planopilaris, and FFA is therefore considered to be a distinct frontal variant of lichen planopilaris $[6,7]$.

\section{Case Report}

A 50-year-old woman presented with frontotemporal recession and partial loss of eyebrows for one year. She had started menopause at the age of 45 years. She had previously been given the diagnosis of androgenetic alopecia and she was treated with topical minoxidil, 2-5\% twice daily, without improvement. The patient spontaneously discontinued the treatment after 3 weeks, about 7 months prior to our visit. On presentation, she did not receive any therapy for hair loss. She had been taking ramipril (5 mg orally every day) for her hypertension since the age of 47 years. Her clinical history, including gynecological data, was otherwise negative. Clinical examination showed frontotemporal recession with uniformly pale skin and loss of follicular orifices where the recession had occurred (fig. $\underline{1} \mathrm{a}, \mathrm{b})$ There was perifollicular erythema at the hair margin and there was also partial loss and erythema of the eyebrows. There were no other skin or mucosal abnormalities. The patient presented only a mild nail fragility after she had started menopause. Laboratory investigations included a full blood count, which was normal, and hormone studies: follicle stimulating hormone, luteinizing hormone, testosterone, thyroid stimulating hormone, which were consistent with postmenopausal levels. Antinuclear antibodies were not detected. The initial clinical findings supported the diagnosis of scarring alopecia. Anamnestic data, with no history of hairdressing associated with traction of scalp hair ruled out the possibility of a traction alopecia. Dermoscopic examination was performed and showed absence of follicular openings, perifollicular scale, and a feeble perifollicular erythema (fig. 1c). A diagnosis of postmenopausal FFA was suspected. A 4-mm scalp punch biopsy from the frontal hairline, at the margin within the hair-bearing area was performed. Histopathology showed some mild chronic lymphocytic inflammatory infiltrate around the infundibular and the isthmus and around the small vessels; a reduction in the number of hair follicles and replacement by fibrous tracts were also evident (fig. 2). There were many intermediate and vellus-like follicles. These features were consistent with the diagnosis of FFA. The patient was treated with a topical steroid (betamethasone dipropionate lotion once a day for 6 months). From the 1-month follow up visit, a treatment with oral hydroxychloroquine was added (200 mg twice a day, for 6 months). The perifollicular erythema at the temporal hair margin was still present but there had been no progression of the frontotemporal recession 3 months since the completion of treatment.

\section{Discussion}

In patients who present with alopecia of the scalp margin, dermoscopy can be very useful, as the differential diagnosis between traction alopecia, alopecia areata, FFA and cicatricial marginal alopecia (CMA) may be difficult [8] (table 1). In our case, there was absence of yellow dots and dystrophic hairs, the most relevant dermoscopic findings of alopecia areata. Anamnestic data ruled out the possibility of a traction alopecia. This was confirmed by the absence of miniaturized hairs, white dots and fractured hair shafts at dermoscopic examination [9]. Dermoscopic findings of CMA recently described by Goldberg, including low hair density and loss of follicular ostia, with thinned shafts of the remaining hairs, were present [10]. However, usually CMA presents with hair loss limited to all the periphery of the scalp, including frontal, temporal and occipital margins. In our case, hair loss involved selectively the frontoparietal region. Moreover, in the case that we report, perifollicular scale and a variable degree of perifollicular erythema were also evident at dermoscopy supporting the diagnosis of FFA. In our case histopathological findings with the presence of a conspicuous inflammatory infiltrate and of many velluslike follicles completely excluded the possibility of a CMA.

The etiology of FFA is yet unknown, but most cases of FFA reported are in postmenopausal women, supporting the idea that hormonal changes may play a role in the etiology $[3,4,11,12]$. FFA may represent a variety of lichen planopilaris with selective 
involvement of certain androgen-dependent areas [3]. The affected follicles may also have typical biologic markers that could explain the clinical and histologic features found in the disease. The fact that FFA is becoming increasingly common may also suggest that environmental factors could be involved in etiology [4]. It is not possible to restart hair growth where follicles have been destroyed, and the aim of treatment must be to arrest hair loss [13-15]. Continuance of recession is not inevitable and in most women it appears that the disease eventually stabilizes. We report our case not only for the rarity of the disease, but because it demonstrates that dermoscopy could improve diagnostic accuracy of hair and scalp disorders.

Table 1. Dermoscopic features of more common hair loss

\begin{tabular}{ll}
\hline Alopecia areata & $\begin{array}{l}\text { Yellow dots, dystrophic hairs, cadaverized (black dots) hair, exclamation } \\
\text { mark hairs }\end{array}$ \\
\hline Androgenetic alopecia & Hair diameter diversity, miniaturized hairs \\
\hline Traction alopecia & $\begin{array}{l}\text { Hairs broken at different distances, miniaturized hairs, white dots and } \\
\text { fractured hair shafts }\end{array}$ \\
\hline Frontal fibrosing alopecia & $\begin{array}{l}\text { Absence of follicular openings, perifollicular scale, and a feeble } \\
\text { perifollicular erythema }\end{array}$ \\
\hline Cicatricial marginal alopecia & $\begin{array}{l}\text { Low hair density and loss of follicular ostia, with thinned shafts of the } \\
\text { remaining hairs }\end{array}$ \\
\hline
\end{tabular}




\begin{tabular}{c|l|l|l}
$\begin{array}{c}\text { Case Reports } \boldsymbol{h} \\
\text { Demmatolagly }\end{array}$ & $\begin{array}{l}\text { Case Rep Dermatol 2010;2:40-45 } \\
\text { D0I: } 10.1159 / 000298283\end{array}$ & Published online: April 8, 2010 & $\begin{array}{l}\text { O 2010 S. Karger AG, Basel } \\
\text { ISSN 1662-6567 } \\
\text { www.karger.com/cde }\end{array}$ \\
\hline
\end{tabular}

Fig. 1. a Frontal recession with uniformly pale skin and loss of follicular orifices; $\mathbf{b}$ temporal recession and slight perifollicular erythema at the hair margin; $\mathbf{c}$ on dermoscopic examination decrease of follicular openings and follicular hyperkeratoses are evident; absence of miniaturization and/or yellow dots.

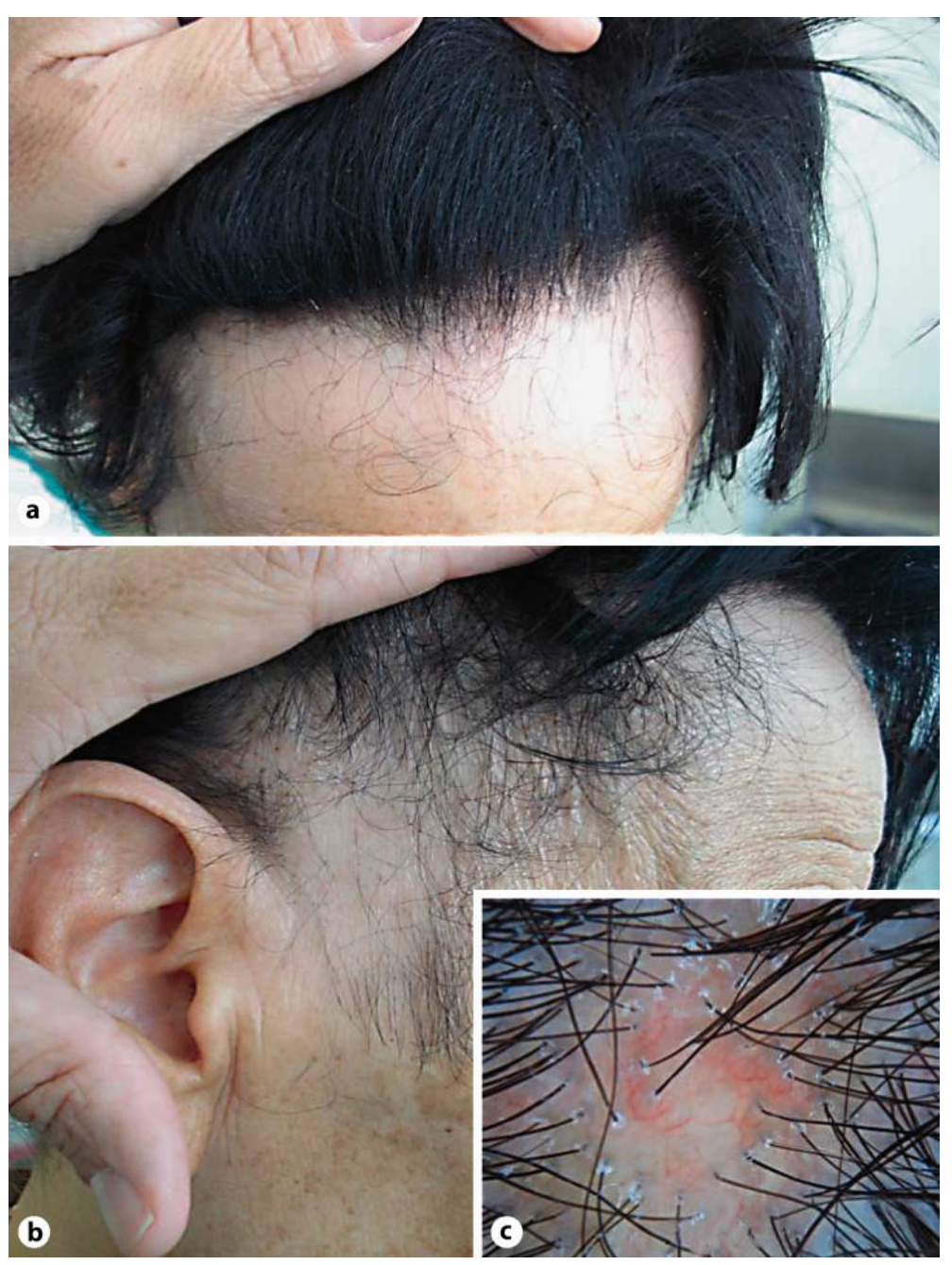




\begin{tabular}{c|l|l|l}
$\begin{array}{c}\text { Case Reports } h \\
\text { Demmatolagy }\end{array}$ & $\begin{array}{l}\text { Case Rep Dermatol 2010;2:40-45 } \\
\text { D0I: } 10.1159 / 000298283\end{array}$ & Published online: April 8, 2010 & $\begin{array}{l}\text { O 2010 S. Karger AG, Basel } \\
\text { ISSN 1662-6567 } \\
\text { www.karger.com/cde }\end{array}$ \\
\hline
\end{tabular}

Fig. 2. Mild chronic lymphocytic inflammatory infiltrate around the infundibular and the isthmus; reduction in the number of hair follicles and replacement by fibrous tracts (hematoxylin-eosin, $\times 5$ ).

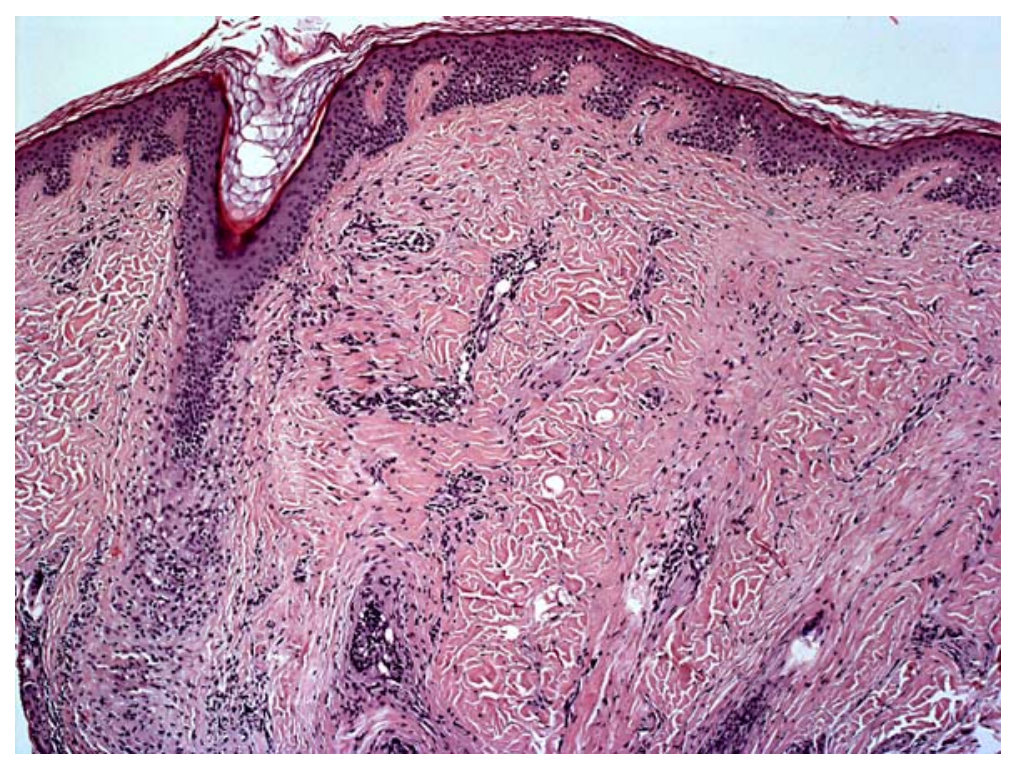




\section{References}

1 Zalaudek I, Argenziano G, Di Stefani A, Ferrara G, Marghoob AA, HofmannWellenhof R, Soyer HP, Braun R, Kerl H: Dermoscopy in general dermatology. Dermatology 2006;212:7-18.

2 Kossard S: Postmenopausal frontal fibrosing alopecia. Scarring alopecia in a pattern distribution. Arch Dermatol 1994;130:770-774.

-3 Tosti A, Piraccini BM, Iorizzo M, Misciali C: Frontal fibrosing alopecia in postmenopausal women. J Am Acad Dermatol 2005;52:55-60.

-4 Tan KT, Messenger AG: Frontal fibrosing alopecia: clinical presentation and prognosis. Br J Derm 2009;160:75-79.

5 Inui S, Nakajima T, Shono F, Itami S: Dermoscopic findings in frontal fibrosing alopecia: report of four cases. Int J Dermatol 2008;47:796-799.

-6 Poblet E, Jiménez F, Pascual A, Piqué E: Frontal fibrosing alopecia versus lichen planopilaris: a clinicopathological study. Int J Dermatol 2006;45:375-380.

7 Kossard S, Lee MS, Wilkinson B: Postmenopausal frontal fibrosing alopecia: a frontal variant of lichen planopilaris. J Am Acad Dermatol 1997;36:59-66.

8 Tosti A, Whiting D, Iorizzo M, Pazzaglia M, Misciali C, Vincenzi C, Micali G: The role of scalp dermoscopy in the diagnosis of alopecia areata incognita. J Am Acad Dermatol 2008;59:64-67.

-9 Yang A, Iorizzo M, Vincenzi C, Tosti A: Hair extensions: a concerning cause of hair disorders. Br J Dermatol 2009;160:207-209.

10 Goldberg LJ: Cicatricial marginal alopecia: is it all traction? Br J Dermatol 2009;160:62-68.

11 Moreno-Ramírez D, Camacho Martínez F: Frontal fibrosing alopecia: a survey in 16 patients. J Eur Acad Dermatol Venereol 2005;19:700-705.

12 Olsen EA: Female pattern hair loss and its relationship to permanent/cicatricial alopecia: a new perspective. J Investig Dermatol Symp Proc 2005;10:217-221.

13 Fiorucci MC, Cozzani E, Parodi A, Rebora A: Frontal fibrosing alopecia. Eur J Dermatol 2003;13:203-204.

14 Georgala S, Katoulis AC, Befon A, Danopoulou I, Georgala C: Treatment of postmenopausal frontal fibrosing alopecia with oral dutasteride. J Am Acad Dermatol 2009;61:157-158.

15 Katoulis A, Georgala, Bozi E, Papadavid E, Kalogeromitros D, Stavrianeas N: Frontal fibrosing alopecia: treatment with oral dutasteride and topical pimecrolimus. J Eur Acad Dermatol Venereol 2009;23:580-582. 